\title{
Risk factors for asthma and cough among Hispanic children in the southwestern United States of America, 2003-2004
}

\author{
Melissa Gonzales, ${ }^{1,4}$ Lorraine H. Malcoe, ${ }^{2,4}$ Orrin B. Myers, ${ }^{1}$ \\ and Judith Espinoza ${ }^{3}$
}

Suggested citation Gonzales M, Malcoe LH, Myers OB, Espinoza J. Risk factors for asthma and cough among Hispanic children in the southwestern United States of America, 2003-2004. Rev Panam Salud Publica. 2007; 21(5):274-81.

ABSTRACT Objectives. To investigate the impact of environmental tobacco smoke (ETS) exposure and mother's place of birth (Mexico vs. United States of America) on the prevalence of asthma and dry nighttime cough among children 2-12 years old residing in the southwestern United States. Methods. Data were collected from November 2003 through March 2004 as part of a health survey of Hispanic mothers with young children who sought emergency, nutrition, or other clinical services. Information about respiratory health was obtained for one randomly selected child per United States-born (no. = 144) or Mexico-born (no. =125) mother. Information on maternal and household sociodemographic variables, smoking, parental asthma, and child's exposure to room or automobile ETS during the previous seven days was also collected. Adjusted prevalence ratios were estimated with modified Poisson regression models.

Results. Most sociodemographic and ETS exposure variables differed significantly by mother's country of birth. Modeled asthma prevalence was 1.95 [95\% confidence interval $(C I)=$ 1.03-3.68] times greater in children of United States-born mothers than children of Mexico-born mothers. This difference persisted after known asthma risk factors were controlled for, including parental asthma, socioeconomic and demographic variables, and child ETS exposure. Childrens' recent automobile ETS exposure was associated with dry nighttime cough [adjusted prevalence ratio $(P R)=1.94,95 \% C I=1.19-3.15]$ and asthma $(P R=2.09 ; 95 \% C I=0.99-4.39)$.

Conclusions. Exposure to ETS in automobiles is an important risk factor for asthma and dry nighttime cough among Hispanic children in the southwest United States, regardless of mother's country of birth. Further research is needed to identify causes of the higher prevalence of asthma in Hispanic children of United States-born mothers.

Key words Asthma; child; child, preschool; cough; Hispanic American; tobacco smoke pollution; United States.

Division of Epidemiology and Biostatistics, Department of Internal Medicine, University of New Mexico Health Sciences Center, Albuquerque, New Mexico, United States of America. Send correspondence and reprint requests to: Melissa Gonzales, Division of Epidemiology and Biostatistics, Department of Internal Medicine, MSC10 5550, 1 University of New Mexico, Albuquerque, New Mexico, 87131-0001, United States of America; e-mail: MGonzales@salud.unm.edu
The prevalence of asthma and respiratory symptoms is on the rise among

2 Faculty of Health Sciences, Simon Fraser University, Burnaby, British Columbia, Canada.

3 Environmental Health Epidemiology Bureau, New Mexico Department of Health, Albuquerque, New Mexico, United States of America.

4 Authors Melissa Gonzalez and Lorraine H. Malcoe contributed equally to this work. minority children in the United States of America, yet relatively little is known about predictors of these conditions among children from diverse Hispanic groups (1-3). Several studies have reported markedly lower prevalences of both child and adult asthma among Mexico-born immigrants to the 
United States compared with United States-born Mexican Americans $(4,5)$. Evaluations of United States Hispanic children living in United StatesMexico border communities have shown lower prevalences of asthma and wheezing for children whose mothers' preferred language was Spanish compared with those whose mothers preferred English. ${ }^{5}$ The United States children of Spanishpreferring mothers had asthma and wheezing prevalence rates similar to those reported for children living on the Mexico side of the border, whereas rates among those with Englishpreferring mothers were more similar to the general United States population $(6,7)$.

To better understand the patterns of asthma and respiratory symptoms among Hispanic children, greater emphasis must be placed on distinguishing social and environmental exposures within Hispanic subgroups at the individual and household levels. For example, smoking rates among Hispanic subgroups vary by acculturation level, gender, income, and education level, with significant differences between United States-born and Mexico-born Hispanics (8-10). Variations across Hispanic subgroups in individual- and household-level risk factors, such as household smoking patterns and children's subsequent exposure to environmental tobacco smoke (ETS), may account for the patterns of asthma and respiratory symptoms observed between United Statesand Mexico-born Hispanic children.

New Mexico is one of four states in the United States that border on northern Mexico. The city of Albuquerque, New Mexico, is located $420 \mathrm{~km}$ north of the international border with Mexico, and is the largest city in the state. Albuquerque's large Hispanic population $(39.9 \%$ in the 2000 census) comprises mainly recent and established immigrants from Mexico as well as na-

\footnotetext{
5 Gonzales M, Neas L. Disparities in asthma status and symptoms among children of Spanish- and English-speaking Hispanics in a United StatesMexico border city [abstract]. J Investigative Med. 2003;51 (Suppl 1):5182.
}

tive Spanish Americans whose forefathers became citizens of the United States after the annexation of presentday New Mexico and southern Colorado in 1848. Previously, we reported that in comparison to Mexico-born mothers, United States-born Hispanic mothers in Albuquerque had a six-fold higher odds of allowing smoking in the home, and a three-fold higher odds of allowing smoking in the family car (11). These increased odds persisted after adjusting for whether the mother or other members of the household smoked. Therefore, ETS exposure metrics that distinguish between room and automobile exposure can provide a more comprehensive measure of children's ETS exposure than simply relying on household smoking indicators alone. This distinction may be particularly important when assessing the impact of ETS exposures incurred by Hispanic children.

In this study we assessed the mother's country of birth and child's recent exposure to ETS in rooms or automobiles in relation to asthma and dry nighttime cough among Hispanic children aged 2-12 years, after taking into account known risk factors for these outcomes.

\section{MATERIALS AND METHODS}

\section{Study population and inclusion criteria}

Data were collected from November 2003 through March 2004 as part of a health survey of Hispanic mothers with young children living in Albuquerque, New Mexico. The study recruitment and survey materials were independently translated into Spanish and verified by back-translation into English by two certified translators. Trained bilingual interviewers recruited participants, obtained informed consent, and conducted personal interviews in the mother's preferred language (Spanish or English). The University of New Mexico Human Subjects Research Review Committee approved the study protocol.
Participants were recruited at the University of New Mexico Hospital pediatric urgent care/emergency room facility, University of New Mexico pediatric and family practice clinics, and nutrition and immunization clinics operated by the state of New Mexico. Appointment logs and sign-in sheets were used to systematically screen women for eligibility. Eligible participants included self-identified Hispanic mothers born either in the United States or Mexico with at least one biological child between 2 and 12 years of age living in their home. The interviews were conducted in private locations in the clinics immediately after eligible mothers signed informed consent forms and had the opportunity to ask questions. Of the 357 eligible mothers identified, 269 completed the survey, for a final sample size of 144 United States-born and 125 Mexico-born mothers. The participation rate was $71 \%$ for Spanish speakers and 83\% for English speakers.

\section{Variables and data recording}

In the survey, the mothers were asked to list the ages of their biological children who currently lived with them. One child aged 2-12 years was randomly selected as the index child for each family. Two respiratory health outcomes, asthma and dry nighttime cough, were ascertained for the index child with standard respiratory health questions (12). Children were classified as having asthma if the mother answered "yes" to at least one of two questions: "Has a doctor or other health professional ever said that (index child) has asthma?" or "In the past 12 months, has (index child) had a wheezy chest, or shortness of breath with wheezing, when he/she did not have a cold?" Children were classified as having dry nighttime cough if the child was classified as nonasthmatic and the mother responded affirmatively to the question, "In the past 12 months, has the child had a dry cough at night, but not any type of wheezing?" Children were classified as asymptomatic if the mother answered "no" to all three questions. 
The index child's recent exposure to ETS was ascertained by asking how many days during the previous seven days he/she had been in a room or car with an active smoker. Additional information obtained about the index children included age, sex, whether they had lived on a farm or ranch or in a rural area before their first birthday, and whether the child had been covered by any type of health insurance during the previous 12 months. If the child's mother or biological father had ever been diagnosed with asthma, the child was considered to have a family history of asthma.

Family poverty level was calculated from data collected about monthly family income and the number of adults and children supported by that income, and was expressed as a percentage of the 2004 United States federal poverty thresholds (13). The United States Government uses the federal poverty thresholds to estimate the number of persons living in poverty each year. Thresholds vary by family size and ages of household members.

\section{Data analysis}

The surveys were optically scanned into an electronic database using Teleforms Elite v.8 (Verity Inc., Sunnyvale, California, United States), and analyzed with version 9 of SAS software (SAS Inc., Cary, North Carolina, United States). Analyses for this study were performed during 2005 and 2006. Differences among groups were tested by chi-square analyses for categorical data and Wilcoxon sum rank tests for continuous data. Adjusted prevalence ratios (PRs) and confidence intervals (CIs) based on robust standard errors were estimated with modified Poisson regression models (14). Models were developed with nonautomated stepwise techniques to identify the relationships between study factors and each of the two primary health outcomes: child's history of diagnosed asthma, wheeze, or both in the previous 12 months, and child's dry nighttime cough without wheeze. Asymptomatic children formed the reference group for

TABLE 1. Child, mother, and household characteristics stratified by mother's country of birth (United States vs. Mexico) reported by 269 Hispanic mothers of children 2 to 12 years old, seen at health-related services in Albuquerque, New Mexico, United States of America, 2003-2004

\begin{tabular}{|c|c|c|c|c|}
\hline Characteristics & $\begin{array}{c}\text { Total } \\
\text { sample } \\
\text { (No. = 269) }\end{array}$ & $\begin{array}{l}\text { United States- } \\
\text { born mother } \\
(\text { No. }=144)\end{array}$ & $\begin{array}{l}\text { Mexico-born } \\
\text { mother } \\
(\text { No. }=125)\end{array}$ & $P^{\mathrm{a}}$ \\
\hline \multicolumn{5}{|l|}{ Child } \\
\hline Mean age in years (standard deviation) & $6.5(3.3)$ & $6.0(3.1)$ & $7.1(3.3)$ & 0.01 \\
\hline Gender, \% male & 45.7 & 42.4 & 49.6 & 0.23 \\
\hline Asthma, \% ${ }^{b}$ & 12.6 & 14.6 & 10.4 & 0.30 \\
\hline Dry nighttime cough, $\%^{c}$ & 26.8 & 31.7 & 21.4 & 0.08 \\
\hline Automobile ETS, \% exposed ${ }^{d}$ & 13.0 & 18.8 & 6.4 & 0.003 \\
\hline Room ETS, \% exposed ${ }^{d}$ & 20.1 & 30.5 & 8.0 & $<0.001$ \\
\hline Lived on farm or in rural area at age $<1$ year, $\%$ & 13.1 & 17.7 & 9.0 & 0.03 \\
\hline Parental history of asthma, \% & 10.4 & 16.7 & 3.2 & $<0.001$ \\
\hline Health insurance in previous year, $\%$ & 77.0 & 95.6 & 54.4 & $<0.001$ \\
\hline \multicolumn{5}{|l|}{ Mother } \\
\hline Mean age in years (standard deviation) & $29.9(6.9)$ & $28.9(6.8)$ & $31.0(6.8)$ & 0.005 \\
\hline Marital status, \% single & 33.5 & 44.4 & 20.8 & $<0.001$ \\
\hline Education, < high school graduate, \% & 41.3 & 22.2 & 63.2 & $<0.001$ \\
\hline Current smoker, \% & 19.7 & 28.5 & 9.6 & $<0.001$ \\
\hline Recruitment site, \% in urgent care facility ${ }^{e}$ & 66.5 & 80.6 & 50.4 & $<0.001$ \\
\hline \multicolumn{5}{|l|}{ Household } \\
\hline Below U.S. federal poverty threshold, $\%^{\dagger}$ & 34.4 & 23.0 & 47.8 & $<0.001$ \\
\hline Other adult smokers in home, \% & 25.3 & 24.3 & 26.4 & 0.69 \\
\hline
\end{tabular}

a Differences among groups were tested by chi-square analyses for categorical data and Wilcoxon sum rank tests for continuous data.

${ }^{b}$ Diagnosis of asthma ever in lifetime, wheeze in the past 12 months, or both. Some children also had dry nighttime cough in the past 12 months.

c Excludes children with a diagnosis of asthma ever in lifetime or wheeze in the past 12 months.

${ }^{\mathrm{d}} \mathrm{ETS}=$ environmental tobacco smoke.

e Mother recruited from the pediatric emergency/urgent care facility vs. primary care clinics.

f Data on household income were missing for 19 children.

both sets of analyses. Any variables that were at least minimally associated with outcomes in the univariate analysis $(P \leq 0.25)$ were tested for inclusion in the multivariate model. Mother's country of birth was retained in both models regardless of significance because it was a primary variable of interest. Other variables were retained in the analysis if they remained statistically significant $(P<0.05)$ or caused confounding of any other explanatory variables. Pairwise interactions were tested between mother's country of birth and each explanatory variable remaining in the final models. No pairwise interactions were statistically significant.

\section{RESULTS}

The prevalence of asthma among index children was $12.6 \% \quad(64.7 \%$ doctor-diagnosed asthma and $79.4 \%$ mother-reported wheeze) (Table 1). The prevalence of dry nighttime cough was $26.8 \%$. Among children of Mexicoborn mothers, the duration of time the mother lived in the United States was not associated with child's dry nighttime cough, asthma, or wheezing.

Compared to children of Mexicoborn mothers, the children of United States-born mothers were younger, had a substantially higher prevalence of exposure to ETS in automobiles or rooms, had lived more often on a farm or in a rural area before their first birthday, and more often had a parental history of asthma. In addition, nearly all children of United Statesborn mothers had health insurance, compared to about half of the children of Mexico-born mothers.

Half $(48 \%)$ of the mothers were interviewed in Spanish. Most (94\%) respondents interviewed in Spanish were born in Mexico. The Mexico-born 
women were primarily from the northern Mexican states of Chihuahua (59\%) and Durango (12\%). These mothers had lived in the United States for a median of 6 years (range 0.5-34 years); $20 \%$ had lived in the United States for less than 2 years. Most (89\%) of the mothers who were interviewed in English were born in the United States. Most United States-born mothers were born in the state of New Mexico $(54 \%)$ or in the adjacent states of Colorado, Arizona, or Texas (24\%).

United States-born and Mexico-born women differed significantly in most demographic variables. United Statesborn women were younger, were less likely to be married, were less likely to live below the federal poverty level, had a higher level of education, and were more likely to smoke (Table 1). There was no difference in the percentage of United States- and Mexico-born mothers who lived in households with other adult smokers. The majority $(81 \%)$ of United States-born mothers were recruited from the pediatric emergency room/urgent care facility, whereas Mexico-born mothers were equally likely to be recruited from the emergency room/urgent care facility as from any other health care facility.

There were significant differences in the distribution of social factors and ETS exposure among children with asthma or dry nighttime cough compared to asymptomatic children (Table 2). In contrast to asymptomatic children, those with dry nighttime cough or asthma had a significantly greater prevalence of parental asthma and of exposure to automobile, but not room, ETS. The children with cough were also more likely to be younger, to be female, to live in poverty, and to have a younger mother. Although more children with cough or asthma had mothers born in the United States (61.9\% and $61.8 \%$, respectively) compared to asymptomatic children $(48.8 \%)$, this difference was not statistically significant in the univariate analysis. Mothers of asymptomatic children were more often $(73.3 \%)$ recruited from the pediatric emergency/urgent care facility than mothers of children with asthma (44.1\%).

TABLE 2. Child, mother, and household characteristics stratified by child's respiratory health status as reported by 269 Hispanic mothers of children 2 to 12 years old, seen at health-related services in Albuquerque, New Mexico, United States of America, 2003-2004

\begin{tabular}{|c|c|c|c|c|c|}
\hline \multirow[b]{2}{*}{ Characteristics } & \multirow{2}{*}{$\begin{array}{c}\text { Asymptomatic } \\
(\text { No. }=172)\end{array}$} & \multicolumn{2}{|c|}{ Dry nighttime cough ${ }^{a}$} & \multicolumn{2}{|c|}{ Asthma $^{b}$} \\
\hline & & (No. = 63) & $P^{\mathrm{c}}$ & (No. = 34) & $P^{c}$ \\
\hline \multicolumn{6}{|l|}{ Child } \\
\hline Mean age in years (standard deviation) & $6.7(3.2)$ & $5.3(2.9)$ & 0.002 & $7.6(3.4)$ & 0.09 \\
\hline Gender, \% male & 48.8 & 31.8 & 0.02 & 55.9 & 0.45 \\
\hline Parental history of asthma, \% & 4.1 & 19.1 & $<0.001$ & 26.5 & $<0.001$ \\
\hline Automobile ETS, \% exposed ${ }^{d}$ & 8.1 & 22.2 & 0.003 & 20.6 & 0.03 \\
\hline $\begin{array}{l}\text { Room ETS, \% exposed } \\
\text { Lived on farm or rural are }\end{array}$ & 20.4 & 20.6 & 0.96 & 17.7 & 0.72 \\
\hline$<1$ year, $\%$ & 11.7 & 17.5 & 0.25 & 11.8 & 0.99 \\
\hline Health insurance in previous year, $\%$ & 73.3 & 84.1 & 0.08 & 82.4 & 0.26 \\
\hline \multicolumn{6}{|l|}{ Mother } \\
\hline Mean age in $y$ & 30.0 & 27.9( & 0.02 & $32.5(8.1)$ & 0.06 \\
\hline Country of birth, \% U.S.-born & 48.8 & 61.9 & 0.08 & 61.8 & 0.17 \\
\hline atus, \% single & 30.8 & 36.5 & 0.41 & 41.2 & 0.24 \\
\hline Education, $\%<$ high school graduate & 41.3 & 42.9 & 0.83 & 38.2 & 0.74 \\
\hline Current smoker, \% & 18.0 & 23.8 & 0.32 & 20.6 & 0.72 \\
\hline Recruitment site, \% in urger & & & & & \\
\hline facilitye & 73.3 & 60.3 & 0.06 & 44.1 & $<0.001$ \\
\hline \multicolumn{6}{|l|}{ Household } \\
\hline Mean percentage of U.S. feder & & & & & \\
\hline threshold (standard deviation) ${ }^{\dagger}$ & $163.0(86.3)$ & $125.0(76.3)$ & 0.001 & $155.1(104.7)$ & 0.19 \\
\hline Other adult smokers in the home, $\%$ & 21.5 & 30.2 & 0.17 & 35.3 & 0.08 \\
\hline
\end{tabular}

a Excludes children with a diagnosis of asthma ever in lifetime or wheeze in the past 12 months.

${ }^{b}$ Diagnosis of asthma ever in lifetime, wheeze in the past 12 months, or both. Some children also had dry nighttime cough in the past 12 months.

${ }^{c}$ Compared with asymptomatic children. Chi-square analyses were performed for categorical data, Wilcoxon sum rank tests were performed for continuous data.

dETS = environmental tobacco smoke.

e Mother recruited from the pediatric emergency/urgent care facility vs. primary care clinics.

${ }^{f}$ Data on household income were missing for 19 children. Less than $100 \%$ of federal poverty threshold indicates the child was living in poverty.

Table 3 shows the adjusted prevalence ratio for dry nighttime cough and asthma estimated by the final multivariate Poisson regression models. The models were adjusted for parental asthma in addition to the explanatory variables shown. There was no association between mother's country of birth and dry nighttime cough. However, mother's country of birth was associated with child asthma. After controlling for recruitment site, which negatively confounded the relationship between mother's country of birth and asthma, we found that the prevalence of asthma was twice as high in children of United States-born mothers as in children of Mexico-born mothers (PR = 1.95; 95\% CI = 1.03-3.68). No other study variables explained the disparity in asthma prevalence between the children of United States-born vs. Mexicoborn mothers.
Recent exposure to ETS in an automobile was associated with a twofold greater prevalence of both asthma $(\mathrm{PR}=2.09,95 \% \mathrm{CI}=0.99-4.39)$ and dry nighttime cough $(\mathrm{PR}=1.94,95 \% \mathrm{CI}=$ 1.19-3.15). Older age and male sex were inversely associated with dry nighttime cough, whereas lower annual household income (per 50\% decrease in household poverty level) was positively associated with cough (PR = $1.33,95 \%$ CI = 1.10-1.61).

\section{DISCUSSION}

This study is the first to examine the influence of tobacco smoke exposure in rooms vs. automobiles, and of mother's country of birth, on the prevalence of asthma and dry nighttime cough among Hispanic children living in the southwestern United States. In chil- 
TABLE 3. Adjusted prevalence of dry nighttime cough and asthma according to survey data from 269 Hispanic mothers of children 2 to 12 years old, seen at health-related services in Albuquerque, New Mexico, United States of America, 2003-2004

\begin{tabular}{|c|c|c|}
\hline Risk factor & $\begin{array}{l}\text { Dry nighttime cougha, } \\
\text { Prevalence ratio }(95 \% \mathrm{Cl})\end{array}$ & $\begin{array}{c}\text { Asthma }{ }^{b, c} \\
\text { Prevalence ratio }(95 \% \mathrm{Cl})\end{array}$ \\
\hline \multicolumn{3}{|l|}{ Mother's country of birth } \\
\hline Mexico & 1.00 & 1.00 \\
\hline United States of America & $1.41(0.85-2.32)$ & $1.95(1.03-3.68)^{d}$ \\
\hline \multicolumn{3}{|l|}{ Child's automobile ETS exposure ${ }^{e}$} \\
\hline No & 1.00 & 1.00 \\
\hline Yes & $1.94(1.19-3.15)^{\dagger}$ & $2.09(0.99-4.39)^{9}$ \\
\hline Child's age (per year increase) & $0.89(0.83-0.96)^{\dagger}$ & $N A^{h}$ \\
\hline \multicolumn{3}{|l|}{ Child's sex } \\
\hline Female & 1.00 & NA \\
\hline Male & $0.56(0.37-0.86)^{\dagger}$ & NA \\
\hline Mother's age (per year increase) & NA & $1.04(1.00-1.09)^{d}$ \\
\hline \multicolumn{3}{|l|}{ Parental history of asthma } \\
\hline No & 1.00 & 1.00 \\
\hline Yes & $1.74(1.04-2.89)^{d}$ & $3.43(1.80-6.56)^{i}$ \\
\hline Family poverty level (per $50 \%$ increase) $)^{\mathrm{j}}$ & $1.33(1.10-1.61)^{\dagger}$ & NA \\
\hline \multicolumn{3}{|l|}{ Recruitment site } \\
\hline Primary care & NA & 1.00 \\
\hline Pediatric emergency/urgent care facility & NA & $0.33(0.19-0.57)^{i}$ \\
\hline
\end{tabular}

${ }^{a}$ Excludes children with a diagnosis of asthma ever in lifetime or wheeze in the previous 12 months.

${ }^{\mathrm{b}}$ Compared with asymptomatic children, and controlling for mother's current smoking status.

${ }^{c}$ Diagnosis of asthma ever in lifetime, wheeze in the past 12 months, or both. Some children also had dry nighttime cough in the past 12 months.

${ }^{d} P<0.05$.

${ }^{\mathrm{e}} \mathrm{ETS}=$ environmental tobacco smoke.

${ }^{f} P<0.01$.

g $P=0.052$.

${ }^{\mathrm{h}} \mathrm{NA}=$ Not applicable. The variable did not remain significant and was not included in the final model.

$P<0.001$.

Prevalence ratio is for a $50 \%$ decline in family income as a percent of the United States federal poverty threshold (i.e., increasing poverty). For example, $50 \%$ vs. $100 \%$ (reference) or $125 \%$ vs. $175 \%$ (reference) of the poverty threshold.

dren of United States-born mothers the prevalence of asthma, after controlling for parental asthma, household smoking, and a range of other known risk factors for childhood asthma, was twice as high as in children whose mothers were born in Mexico. After adjusting for these same risk factors, we found the child's recent exposure to ETS in an automobile to be associated with a twofold higher prevalence of dry nighttime cough. These findings highlight the importance of automobile ETS exposure and mother's country of birth as risk factors for pediatric respiratory illness among Hispanic children living in the southwestern United States.

The finding that automobile, but not room, ETS exposure was associated with child asthma and dry nighttime cough is unique, but not unexpected. An association between ETS exposure and cough has previously been demonstrated in children, although the lo- cation of exposure was not specified $(15,16)$. Unlike a room, which has a large volume of air that dilutes ETS, the smaller volume of an automobile passenger compartment presents an opportunity for acute, high-concentration exposures to the air pollutants present in secondhand tobacco smoke. Repace (17) estimated that the concentration of respirable particulate matter inside a closed automobile where three cigarettes had been smoked could reach double the concentration shown to induce endothelial dysfunction in ETSexposed nonsmokers, and three times the concentration measured in a bingo hall (18). The concentration of secondhand smoke inside an automobile is similar to the levels encountered in bars, casinos, and other venues where smoking is permitted. Given the potentially substantial impact of automobile ETS exposure on child respiratory health, encouraging Hispanic parents to opt for smoke-free environments, and particularly smoke-free vehicles, may be an important public health intervention in reducing respiratory illness in Hispanic children.

The relatively low rates of parental history of asthma, wheezing without a cold, and doctor-diagnosed asthma in our sample of children of Mexico-born mothers are similar to the rates noted in previous standardized studies in Mexico and among Mexico-born children living in the United States $(4,6)$. A recent reanalysis of data from several national surveys showed a higher prevalence of asthma in United Statesborn than in Mexico-born Mexican Americans (5). Previous investigators have reported significant variability in "protective factors" for child asthma (e.g., a greater prevalence of twoparent households and lower rates of smoking) among Hispanic mothers who were less acculturated to life in the United States compared to those who were more acculturated or were United States-born (19). We found similar differences in these and other potential explanatory variables between United States- and Mexico-born mothers. Our findings are also consistent with previous evaluations of Hispanic persons living in the southwestern United States, which found a higher prevalence of asthma and wheezing among children with more acculturated mothers (as indicated by English versus Spanish language preference; see footnote 5).

It could be argued that the observed difference in the prevalence of asthma between children of United States- and Mexico-born mothers residing in the United States results from inequities in health care access and subsequent diagnosis. Indeed, the rate of doctordiagnosed asthma we observed among children of Mexico-born mothers (4.8\%) was about half the rate reported by United States-born mothers (11.1\%). To minimize the influence of differential diagnosis rates for asthma by mother's country of birth, we used an expanded definition of asthma that included both physician-diagnosed asthma and mother-identified wheezing without a cold. The asthma rates 
produced by this definition $(14.6 \%$ among children of United States-born mothers, $10.4 \%$ among children of Mexico-born mothers) are similar to those observed in the general population of the United States for children aged $0-4(7.5 \%)$ and $5-11$ years $(14.0 \%)$ (7). It has been further argued that longer duration of residence in the United States is associated with increased access to health care, and may lead not only to higher rates of asthma diagnosis, but also to a change in the way wheezing is perceived and reported (20). However, we found no association between duration of the mothers' residence in the United States and reported asthma, wheezing, or dry nighttime cough among children of Mexico-born mothers.

Our sample was recruited from a pediatric emergency room/urgent care facility and from primary care clinics. As expected, we found that United States-born mothers were more often recruited from the pediatric emergency facility. We examined whether recruitment site could explain the observed difference in the prevalence of child asthma between United States- vs. Mexico-born mothers. One previous study indicated that asthma is more common among low-income minority children who receive health care in the emergency room rather than through regular health care facilities (21). In contrast with these findings, our data showed that recruitment from the emergency care facility was associated with a substantially lower prevalence of asthma. Further, the observed difference in the prevalence of asthma between children of United States- and Mexico-born mothers persisted after we controlled for recruitment site, and we found no significant interactions between recruitment site and mother's country of birth. Thus, we think it unlikely that differential access to primary health care accounted for the observed disparity in prevalence by mother's country of birth.

European studies suggest that early lifetime exposure in rural and farming communities may confer a protective effect against the development of asthma and allergy (22). Rural-to- urban migration has been cited as a possible reason for lower asthma rates in Mexican immigrants (5). We found that twice as many children of United States-born mothers as Mexico-born mothers had lived on a farm or in a rural area prior to their first birthday, but found no indication that rural-tourban migration was associated with differences in child respiratory health. Previous studies have emphasized the association of environmental exposures and asthma among Mexican migrants in the United States. $(4,5)$. Our findings indicate a role for environmental and social risk factors in child asthma and dry nighttime cough among both migrant and established Hispanic populations in the southwestern United States.

We also observed a clear relationship between increased family poverty and nighttime cough. Previous studies have reported cough to be the respiratory symptom most strongly associated with low socioeconomic status (23-25). Although the mechanisms by which economic deprivation might cause cough are unknown, differences in parental smoking and variations in household conditions, reporting, or medication use are possible explanations (23). We found that the association between poverty and nighttime cough persisted after we controlled for mother's smoking, parental asthma, and ETS exposures. The finding that poverty level as well as children's gender and age were associated with dry nocturnal cough but not with asthma suggests that the causes of these two respiratory outcomes may differ.

Our study is subject to the limitations inherent in any cross-sectional survey. First, we could not determine the temporal relationship between exposures and respiratory outcomes. Longitudinal studies are needed to examine predictors of the incidence of asthma in children of United Statesand Mexico-born Hispanics. Second, our data relied on maternal selfreports, which may have resulted in misclassification of exposure or outcome variables. Such misclassification is likely to be nondifferential and thus would tend to attenuate the observed associations. Studies that included biomarker and environmental measures of ETS have found that objective measures of ETS exposure are often somewhat higher than those based on selfreports $(26,27)$. Misclassification of "exposed" children as "unexposed" would likely have underestimated the observed associations between ETS exposures and child respiratory outcomes. This bias may explain why we did not observe an association between room ETS exposure and cough or asthma, and may mean that the true association between automobile ETS exposure and respiratory outcomes is even greater than we observed. Third, the prevalence of child asthma and symptoms was based on mothers' reports rather than objective pulmonary function measures. We nonetheless believe that the reported frequencies of children's respiratory symptoms, diagnosis of asthma, and history of parental asthma are reliable because they are similar to the frequencies reported in previous studies of Mexican American and Mexican children in the same geographical region, and reflect the expected rate differential in diagnosed asthma for United States- vs. Mexicoborn Hispanics $(5,6,28)$.

Despite higher poverty rates, less education, and worse access to health care, the health outcomes of many Hispanics living in the United States today are equal to, or better than, those of non-Hispanic whites, a situation described as the Hispanic health paradox. We observed that this health advantage is not enjoyed equally across Hispanic subgroups living in the same community and accessing similar health services. Our data showed that compared to children of Mexico-born women, the higher prevalence of asthma in Hispanic children of United States-born women persisted after known asthma risk factors were controlled for, including history of parental asthma, socioeconomic and demographic variables, and children's ETS exposure. Further research is needed to understand the underlying causes of this disparity. In addition, our findings indicate that automobile ETS exposure is an important risk fac- 
tor for both asthma and dry nighttime cough among children of both United States- and Mexico-born Hispanic women residing in the southwestern United States, since more than one in five children with respiratory outcomes had been exposed to automobile ETS during the seven days before the survey. This proportion may well increase as the Hispanic population in the United States grows and more women belong to the high-risk United States-born group, among whom active smoking is more prevalent (9).
Additional research in larger Hispanic populations is needed to assess the pathophysiologic impact of children's exposure to ETS indoors and in automobiles. In the meantime, public health professionals should consider assessing the full range of ETS exposures routinely experienced by children when evaluating respiratory symptoms and developing intervention strategies to reduce exposure.

Acknowledgments. The New Mexico Tobacco Settlement Increase Award for fiscal year 2003 funded this study and provided support for three authors (MG, LHM, and JE). LHM was also supported by other New Mexico Tobacco Settlement funds appropriated to the University of New Mexico and allocated to the Institute for Public Health at the University of New Mexico School of Medicine. The study also received support from the New Mexico Center for Environmental Health Sciences (NIEHS Grant P30-ES-012072).

\section{REFERENCES}

1 Aligne CA, Auinger P, Byrd R.S, Weitzman M. Risk factors for pediatric asthma: contributions of poverty, race, and urban residence. Am J Resp Crit Care Med. 2000;62:873-7.

2 Nsouli TM. Inner-city disadvantaged populations and asthma prevalence, morbidity, and mortality. Ann Allergy Asthma Immunol. 1999;82:2-4.

3 Mitka M. Why the rise in asthma? New insight, few answers. JAMA. 1999;281:2171-2.

4 Eldeirawi K, McConnell R, Freels S, Persky VW. Associations of place of birth with asthma and wheezing in Mexican American children. J Allergy Clin Immunol. 2005;116: 42-8.

5 Houlgin F, Manino DM, Anto J, Ford ES, Teague WG, Redd SC, et al. Country of birth as a risk factor for asthma among Mexican Americans. Am J Respir Crit Care Med. 2005; 171:103-8

6 Villarreal, AB, Aguirre LHS, Rojo MMT, Navarro ML, Romieu I. Risk factors for asthma in school children from Ciudad Juarez, Chihuahua. J Asthma. 2003;40:413-23.

7. United States of America. Centers for Disease Control. QuickStats: percentage of children aged $<18$ years who have ever had asthma diagnosed, by age group-United States, 2003. MMWR. 2005;54:412.

8. Kaplan CP, Napoles-Springer A, Stewart SL, Pérez-Stable EJ. Smoking acquisition among adolescents and young Latinas: the role of socioenvironmental and personal factors. Addict Behav. 2001;26:531-50.

9. Caraballo RS, Lee CW. Consumo de tabaco entre los mexicanos y sus descendientes, en Estados Unidos de América. Salud Publica Mex. 2004;46:241-50.

10. Acevedo MC. The role of acculturation in explaining ethnic differences in prenatal healthrisk behaviors, mental health and parenting beliefs of Mexican American and European American at-risk women. Child Abuse Negl. 2000;24:111-27.

11. Gonzales M, Malcoe L, Espinoza J, Kegler MC. Prevalence and predictors of home and automobile smoking bans and child environmental tobacco smoke exposure: a crosssectional study of United States- and Mexicoborn Hispanic women with young children. BMC Public Health 2006; 6:265.

12. Ferris BG. Epidemiology Standardization Project (American Thoracic Society). Am Rev Respir Dis. 1978;118(6):1-120.

13. United States of America, Census Bureau. Poverty thresholds 2004. Available from: http://www.census.gov/hhes/poverty/ threshld/thresh04.html. Accessed 20 October 2004.

14. Zou G: A modified Poisson regression approach to prospective studies with binary data. Am J Epidemiol. 2004;159:702-6.

15. Swartz J, Timonen KL, Pekkanen J. Respiratory effects of environmental tobacco smoke in a panel study of asthmatic and symptomatic children. Am J Respir Crit Care Med. 2000;161:802-6

16. Gibson PG, Simpson JL, Chalmers AC, Toneguzzi RC, Wark PA, Wilson AJ, et al. Airway eosinophilia is associated with wheeze but is uncommon in children with persistent cough and frequent chest colds. Am J Respir Crit Care Med. 2001;164:977-81.

17. Repace, J. Effects of passive smoking on coronary circulation. JAMA. 2002;287:316-7.

18. Otsuka R, Watanabe H, Hirata K, Tokai K, Muro T, Yoshiyama M, et al. Acute effects of passive smoking on the coronary circulation in healthy young adults. JAMA. 2001;286: 436-41.

19. Klinnert MD, Price MR, Liu AH, Robinson JL. Unraveling the ecology of risks for early childhood asthma among ethnically diverse families in the southwest. Am J Public Health. 2002;92:792-8.

20. Gold DR, Acevedo-Garcia D. Immigration to the United States and acculturation as risk factors for asthma and allergy. J Allergy Clin Immunol. 2005;116:38-41.

21. Simpson L, Owens PL, Sodet MW, Chevarley FM, Dougherty D, Elixhauser A, et al. Health care for children and youth in the United States: Annual report on patterns of coverage, utilization, quality, and expenditures by income. Ambul Pediatr. 2005;5:6-44.

22. Braun-Fahrlander C, Reidler J, Herz U, Eder W, Waser M, Grize L, et al. Environmental exposure to endotoxin and its relation to asthma in school-age children. $\mathrm{N}$ Engl J Med. 2002;347: 869-77.

23. Ng Mann Kwong. Diagnostic and treatment behaviour in children with chronic respiratory symptoms: relationship with socioeconomic factors. Thorax. 2002;57:701-4.

24. Ernst P, Eemissie K, Joseph L, Locher U, Becklake MR. Socioeconomic status and indicators of asthma in children. Am J Respir Crit Care Med. 1995;152:570-5.

25. SIDRIA. Asthma and respiratory symptoms in 6-7 year old Italian children. Eur Respir J. 1997;10:1780-6.

26. Sexton K, Adgate JL, Church TR, Hecht SS, Ramachandran G, Greaves IA, et al. Children's exposure to environmental tobacco smoke: using diverse exposure metrics to document ethnic/racial differences. Environ Health Perspect. 2004;112:392-7.

27. Emmons KM, Wong M, Hammond SK, Velicer WF, Fava JL, Monroe AD, et al. Intervention and policy issues related to children's exposure to environmental tobacco smoke. Prev Med. 2001;32:321-31.

28. Neas L, Gonzales M, Mukerjee S, Smith L, Svendsen E, Ross R, et al. GIS-modeled indicators of traffic-related air pollutants and adverse health effects among children in El Paso, Texas, USA. Epidemiology (in press).

Manuscript received on 14 July 2006. Revised version accepted for publication on 12 May 2007 
RESUMEN Objetivos. Se investigó el impacto de la exposición al humo ambiental del tabaco (HAT) y del país de nacimiento de la madre (México frente a los Estados Unidos de América) en la prevalencia de asma y tos seca nocturna en niños de 2-12 años de edad

\section{Factores de riesgo de asma y tos en niños hispanos en el suroeste de los Estados Unidos de América, 2003-2004}

que viven en el suroeste de los Estados Unidos de América.

Métodos. Los datos se colectaron de noviembre de 2003 a marzo de 2004 como parte de una encuesta de salud de madres hispanas con hijos pequeños, que solicitaron servicios de emergencia, nutrición o clínicos. Se obtuvo la información sobre el estado de salud respiratoria de un hijo seleccionado aleatoriamente por cada madre nacida en los Estados Unidos de América $(n=144)$ o en México $(n=125)$. Se colectó información sobre las variables sociodemográficas de la madre y del hogar, el hábito de fumar, los antecedentes de asma de los padres y la exposición del niño al HAT en habitaciones o automóviles en los siete días previos. Las razones de prevalencia ajustadas se estimaron mediante modelos de regresión de Poisson modificados.

Resultados. La mayoría de las variables sociodemográficas y de exposición al HAT presentaron diferencias significativas según el país de nacimiento de la madre. La prevalencia de asma según el modelo fue de 1,95 (intervalo de confianza de 95\% $[\mathrm{IC} 95 \%]=1,03$ a 3,68) veces mayor en niños de madres nacidas en Estados Unidos de América que en los de madres nacidas en México. Esta diferencia se mantuvo después de controlar por los factores de riesgo de asma conocidos, entre ellos los antecedentes de asma de los padres, las variables socioeconómicas y demográficas y la exposición del niño al HAT. La exposición reciente del niño al HAT en automóviles se asoció con la tos seca nocturna (razón de prevalencia ajustada [RP] =1,94; IC95\% =1,19 a 3,15) y asma ( $\mathrm{RP}=2,09$; IC95\% = 0,99 a 4,39).

Conclusiones. La exposición al HAT en automóviles es un importante factor de riesgo de asma y de tos seca nocturna en niños hispanos en el suroeste de los Estados Unidos de América, independientemente del país de nacimiento de la madre. Se requieren más investigaciones para identificar las causas de la alta prevalencia de asma en los niños hispanos de madres nacidas en los Estados Unidos de América.

Palabras clave Asma, niño, tos, hispanoamericanos, contaminación por humo de tabaco, Estados Unidos.

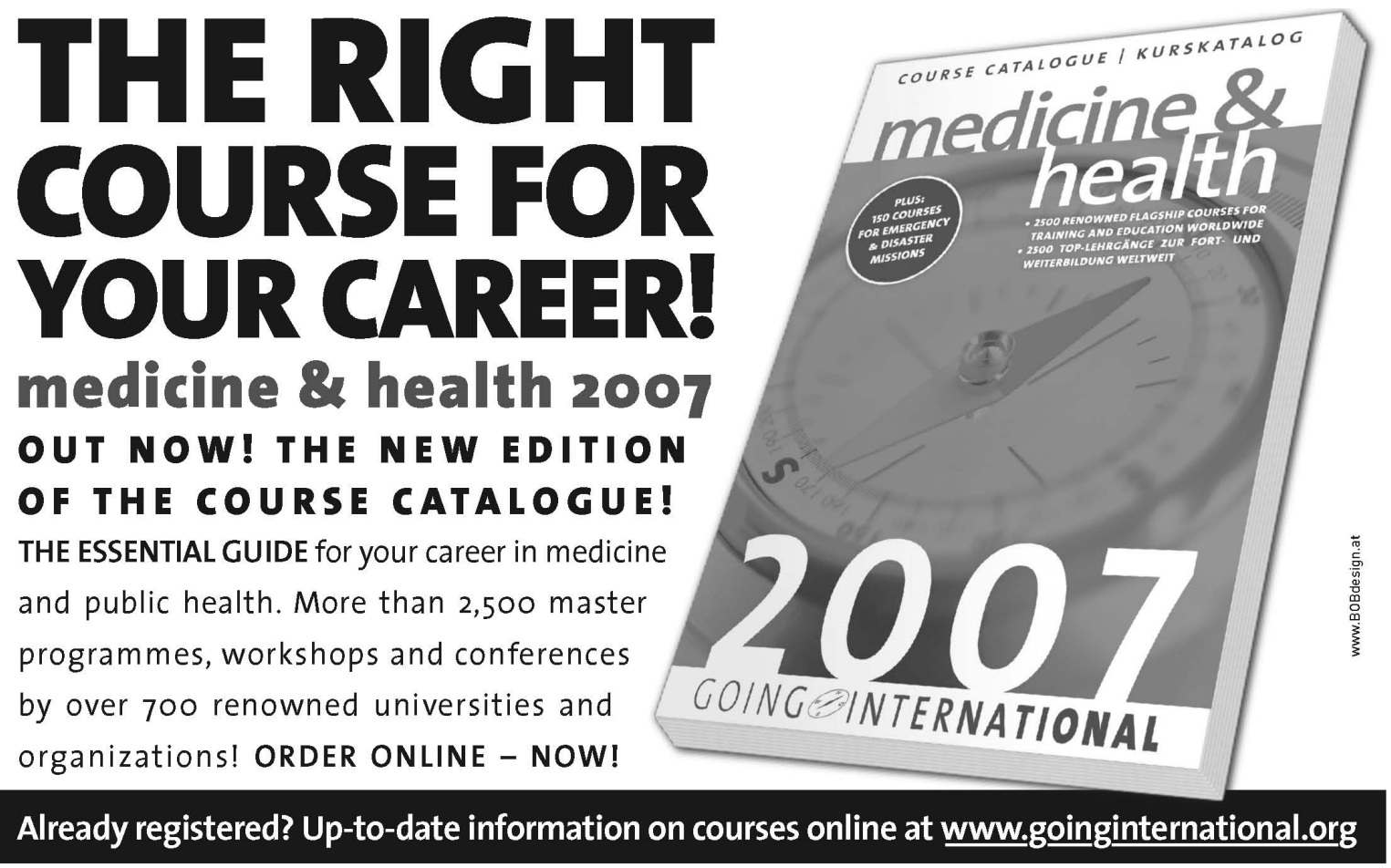

